\title{
Assessment of Knowledge, Attitude and Practice of Breast Self-Examination among Reproductive Age Females in Altekaina Village, Sudan July 2018
}

\author{
Wafaa Babiker Ali Mohammed*, Nourelhuda Mustafa Abdalla Ali and Bashir Alhady Bashir
}

Faculty of Medicine, University of Bahri, Sudan

${ }^{*}$ Corresponding author: Wafaa Babiker Ali Mohammed, Faculty of Medicine, University of Bahri, Sudan, Tel: +249124534028; E-mail: alwafa1995@hotmail.com

Received: 25 Jan, 2019 | Accepted: 08 Mar, 2019 | Published: 14 Mar, 2019

Citation: Ali Mohammed WB, Abdalla Ali NM, Bashir BA (2019) Assessment of Knowledge, Attitude and Practice of Breast Self-Examination among Reproductive Age Females in Altekaina Village, Sudan July 2018. Int J Canc Res Mol Mech 5(1): dx.doi.org/10.16966/2381-3318.143

Copyright: (c) 2019 Ali Mohammed WB, et al. This is an open-access article distributed under the terms of the Creative Commons Attribution License, which permits unrestricted use, distribution, and reproduction in any medium, provided the original author and source are credited.

\section{Introduction}

\section{Background}

Breast cancer is the most common female cancer in both developing and developed countries. It is also the leading cause of cancer death in women between the age 18 and 54years old [1]. The incidence and mortality of breast cancer are increasing in Africa and Asia [2]. Advances in medicine have shown that one-third of all cancers are preventable and a further one-third is potentially curable if diagnosed early $[1,2]$. It is also the leading cause of cancer death in women between the ages of 15 and 54 years [2].

Breast Self-Examination (BSE), Clinical Breast Examination (CBE) and mammograms are important, available, and advisable methods used for detecting breast cancer in the early stage [3].

According to ACS, breast cancer (BC) makes up (25\%) of all new cancer diagnoses in women globally. In 2012, nearly 1.7 million new cases were diagnosed worldwide. Survival rates vary worldwide but are improving overall. In countries with advanced care, the rate is $(80 \%)$ to $(90 \%)$ for those with a first-stage diagnosis, and (24\%) if diagnosis occurs at a later stage [4]. BC constitutes (13-35\%) of all female cancers. A recent rise of Age-Standardized Incidence Rates (ASR) is noted. Advanced disease remains very common in Egypt, Tunisia, Saudi Arabia, Syria, Palestinians and others. Mastectomy is still performed in more than $(80 \%)$ of women with breast cancer [5]. Women living in central Sudan encompassing al-Gezira, Blue Nile, White Nile, and Sennar States. Cases comprised 1255 women from central Sudan diagnosed with breast cancer and referred to and treated at Institute of Nuclear Medicine, Molecular Biology, and Oncology, from January 1999 to December 2006 [6].

Most successful approach to decrease mortality due to breast cancer is the application of secondary prevention; breast selfexamination (BSE), breast clinical examination and mammogram. Most of developing countries are unable to provide mammograms to all women at high risk, and most women do not have the financial ability to cover the cost $[3,7]$.
Breast self-examination (BSE) is a "procedure in which a woman inspects and examines her breasts and their accessory structures for evidence of change that could indicate an abnormal process. It is one of the three tests the American Cancer Society (ACS) recommends in order to help detect breast cancer in its earliest stages" [8].

The breast cancer's severity increase with age and family history of breast cancer so its prognosis will be poor thus the early identification of breast cancer signs by BSE $[2,9,10]$ will decrease the severity of the disease through proper management during early period [7].

\section{Justification}

Despite the advent of modern screening methods, more than (90\%) of cases of cancers of the breast in Sudan are detected by women themselves, stressing the importance of breast self-examination. Moreover, it is observed that breast cancer presents late in the advanced stages. Hence, in this study, we will assess the knowledge and practice of reproductive age females regarding BSE because it is a very important to reveals breast cancer symptoms on any patient in early stages by herself with less effort and cost.

\section{Objectives}

General: To determine knowledge, attitude and practice of village females regarding breast self-examination.

Specific: To determine the level of knowledge about self-examination.

To determine practice of self-examination.

To determine attitude of self-examination.

To identify the relationships between sociodemographic variables (age, educational level) and level of knowledge.

\section{Materials and Methods}

\section{Study design}

Descriptive cross-sectional community-based study was conducted among 18-45 years females in Altekaina village to assessed knowledge, attitude and practice of BSE in June 2018. 


\section{Study area}

Altekaina village is located in Almassed unit, $\mathrm{Al}$ kamlin district, $\mathrm{Al}$ Gezira state. Altekaina is about 70km south of the state of Khartoum and bordered on the east by Blue Nile and on the west by Khartoum-Madani Street, on the north by Ummaged village and on south by Al Bshagra gharb village. The area altekaina is 3 square $\mathrm{km}$ long and $1 \mathrm{~km}$ wide. According to 2017 statistical count, population capacity was 18800 citizens, and the number of females 9000 , nearly half of them was housewives.

\section{Study population}

Reproductive age females $18-45$ years.

Sample size $(\mathrm{n})=384$ female.

Selection and inclusion criteria: This study included every female between 18-45 years, we divided the village to four blocks every block contains approximability 250 houses, so we selected every $10^{\text {th }}$ house to contain. Any female who under gone mastectomy and not originally from Altekaina were excluded from the study.

\section{Study variables}

1. Knowledge, attitude regards BSE.

2. Sociodemographic: age, social status, educational level, occupation.

3. Performance of participants on practice.

\section{Study tools}

Knowledge, attitude and practice measured by interview questionnaire.

\section{Method of data collection}

Females included in study based on systemic random method. Self-administered pre-tested close-ended questionnaire \# used which contained the following sections:

Section A: Personal and sociodemographic data such as age, educational level and marital status, Family history of breast cancer.

Section B: Contained four items regarding their knowledge about BSE. We included questions about whether they know BSE and the meaning of it and the resources they learnt it from. We also asked details about the age and time at which BSE must be performed, whether they believe in its efficacy. Three marks were given for a correct answer; 2 marks for answering I don't know; and 1 mark for an incorrect answer. The score for the knowledge items ranged between 4 and 12. Participants with an excellent knowledge of BSE would score between 10 and 12 marks; participants with an average knowledge of BSE would score between 5 and 9; while participants with a poor knowledge of BSE would score between 0 and 4 marks. Questions about their attitude regarding BSE.

Also contained five items on the practice of BSE. The participants were asked to report whether or not they practice BSE; how often they practice BSE; at what time they practice BSE; if they knew the five correct steps of performing BSE. No specific score would be awarded for this section.

\section{Analysis}

Data were analyzed using statistical package for social science (SPSS) version 21. We used chi square test to define the relationships between (age, educational level) and level of knowledge.

\section{Ethical consideration}

Permission to collect data was requested and obtained from popular committee of village. All data included in this research was collected after approval verbal informed consent from all participants and this research document information followed all research ethical guidelines in collection and present.

\section{Results}

A total of 384 reproductive age females from Altekaina were targeted participated in this study. All of them complete the questionnaire of this study giving a response rate of (100\%). The age of the participants ranged from 18 to 45 years.

Section A: Respondents' demographic data (Table 1).

Section B: Respondents' knowledge, attitude and practice of BSE (Tables 2-5) (Figures 1-5).

Table 1: Respondents' sociodemographic characteristics $(n=384)$.

\begin{tabular}{|c|c|c|}
\hline Variable & Frequency & Percentage \\
\hline \multicolumn{3}{|l|}{ Age } \\
\hline $18-25$ & 151 & 39.3 \\
\hline $26-30$ & 84 & 21.9 \\
\hline 31-35 & 43 & 11.2 \\
\hline $36-40$ & 64 & 16.7 \\
\hline 41-45 & 42 & 10.9 \\
\hline \multicolumn{3}{|c|}{ Level of education } \\
\hline Primary & 56 & 14.6 \\
\hline Intermediate & 35 & 9.1 \\
\hline High school & 168 & 43.8 \\
\hline University & 97 & 25.3 \\
\hline Khalawi & 28 & 7.3 \\
\hline \multicolumn{3}{|l|}{ Social status } \\
\hline Single & 63 & 16.4 \\
\hline Married & 234 & 60.9 \\
\hline Divorced & 56 & 14.6 \\
\hline Widowed & 31 & 8.1 \\
\hline \multicolumn{3}{|l|}{ Occupation } \\
\hline Governmental & 54 & 14.1 \\
\hline Private & 36 & 9.4 \\
\hline Freestyle & 23 & 6 \\
\hline Housewife & 257 & 66.9 \\
\hline Student & 14 & 3.6 \\
\hline
\end{tabular}

Table 2: Respondents' knowledge of definition of BSE ( $n=384)$.

\begin{tabular}{|l|c|c|}
\hline \multicolumn{1}{|c|}{ Knowledge } & Frequency & Percentage \\
\hline Poor & 154 & 40.1 \\
\hline Average & 110 & 28.6 \\
\hline Excellent & 120 & 31.3 \\
\hline
\end{tabular}

Table 3: Respondents' knowledge of definition of BSE according to age category $(n=384)$.

\begin{tabular}{|c|c|c|c|c|}
\hline \multirow{2}{*}{ Age } & \multicolumn{3}{|c|}{ Level of knowledge } & \multirow{2}{*}{ Total } \\
\hline & Poor & Average & Excellent & \\
\hline $18-25$ & 55 & 55 & 41 & 151 \\
\hline $26-30$ & 39 & 13 & 32 & 84 \\
\hline $31-36$ & 15 & 12 & 16 & 43 \\
\hline $37-40$ & 32 & 15 & 17 & 64 \\
\hline $41-45$ & 14 & 13 & 15 & 42 \\
\hline
\end{tabular}


Table 4: Chi Square Test to define the relationships between age and level of knowledge.

\begin{tabular}{|c|c|c|c|c|}
\hline Level of knowledge & \multicolumn{3}{|c|}{ Aoor } & \multicolumn{2}{c|}{ Excellent } \\
\hline Age & \multicolumn{3}{|c|}{ Row Totals } \\
\hline $18-25$ & $55(60.95)[0.58]$ & $55(42.47)[3.70]$ & $41(47.58)[0.91]$ & 151 \\
\hline $26-30$ & $39(33.91)[0.77]$ & $13(23.62)[4.78]$ & $32(26.47)[1.16]$ & 84 \\
\hline $31-36$ & $15(17.36)[0.32]$ & $12(12.09)[0.00]$ & $16(13.55)[0.44]$ & 43 \\
\hline $37-40$ & $32(25.83)[1.47]$ & $15(18.00)[0.50]$ & $17(20.17)[0.50]$ & 64 \\
\hline $41-45$ & $14(16.95)[0.51]$ & $13(11.81)[0.12]$ & $15(13.23)[0.24]$ & 42 \\
\hline Column Totals & 155 & 108 & 121 & 384 \\
\hline
\end{tabular}

The chi-square statistic is 15.9908 . The $p$-value is .042512 . The result is significant at $p<.05$.

Tables 5: Chi Square Test to define the relationships between educational level and level of knowledge.

\begin{tabular}{|l|l|l|l|l|}
\multicolumn{1}{|c|}{ Level of knowledge } & \multicolumn{2}{c|}{ Average } & Eoor \\
\hline Educational level & \multicolumn{3}{c|}{ Row Totals } \\
\hline Primary & $32(22.06)[4.48]$ & $18(15.76)[0.32]$ & $5(17.19)[8.64]$ & 55 \\
\hline Intermediate & $18(13.64)[1.40]$ & $10(9.74)[0.01]$ & $6(10.62)[2.01]$ & 34 \\
\hline High school & $66(67.38)[0.03]$ & $55(48.12)[0.98]$ & $47(52.50)[0.58]$ & 168 \\
\hline University & $24(38.90)[5.71]$ & $22(27.79)[1.21]$ & $51(30.31)[14.12]$ & 97 \\
\hline Khalawi & $14(12.03)[0.32]$ & $5(8.59)[1.50]$ & $11(9.38)[0.28]$ & 30 \\
\hline Column Totals & 154 & 110 & 120 & 384 (Grand Total) \\
\hline
\end{tabular}

The chi-square statistic is 41.5856 . The $p$-value is $<0.00001$. The result is significant at $p<.05$.

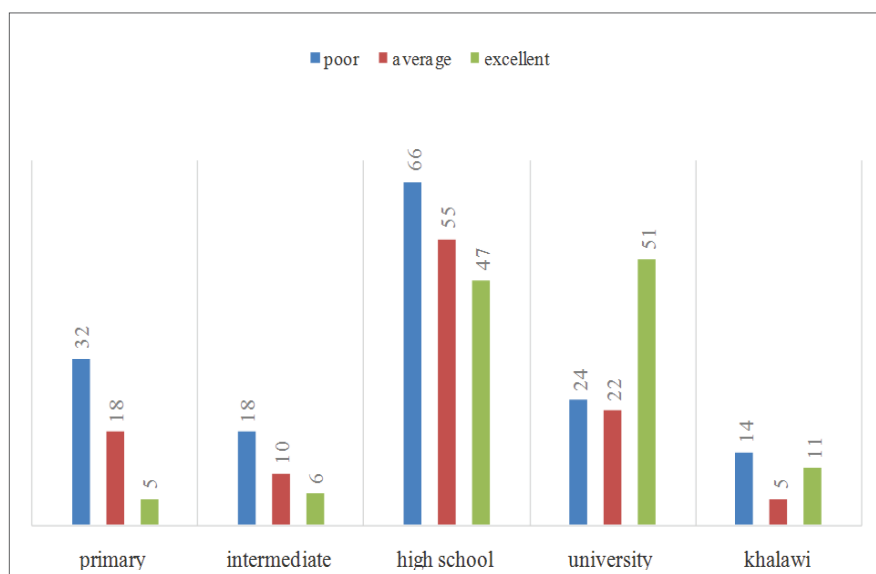

Figure 1: Respondents' knowledge of definition of BSE according to educational level $(n=384)$.

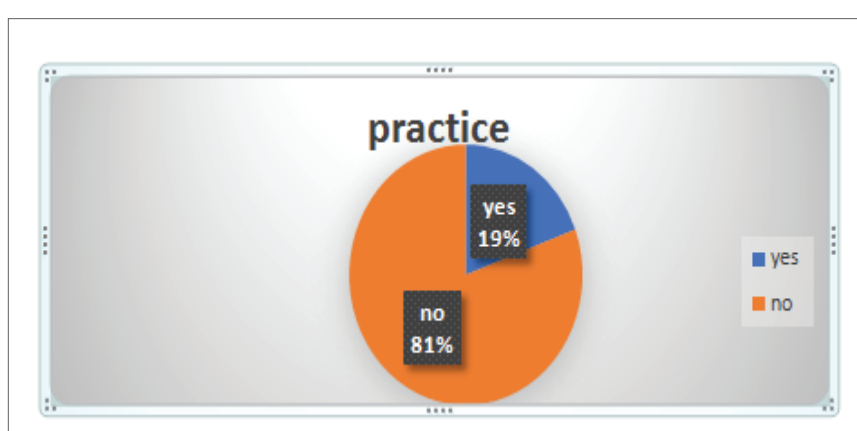

Figure 2: Respondents' performance of BSE ( $n=384)$.

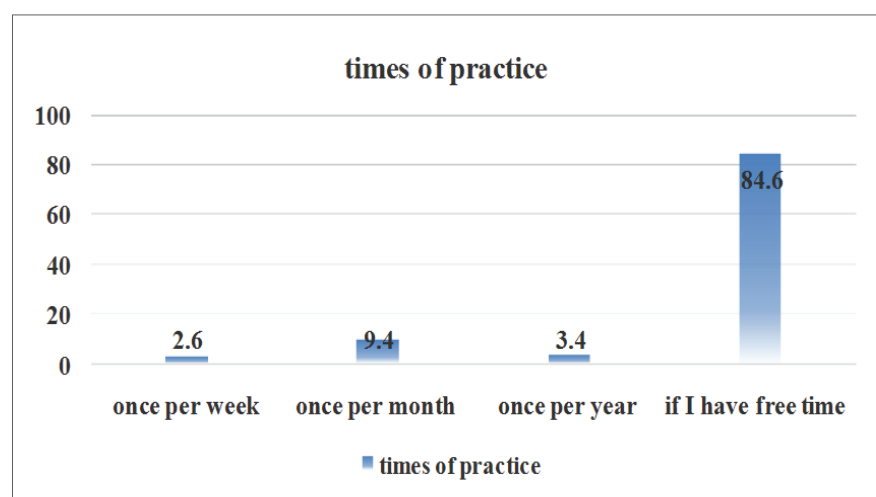

Figure 3: Respondents' frequency of performing BSE (total number of BSE performers, $n=74)$.

\section{KNOWLEDGE OF RIGHT TECHINIQUE OF BSE}

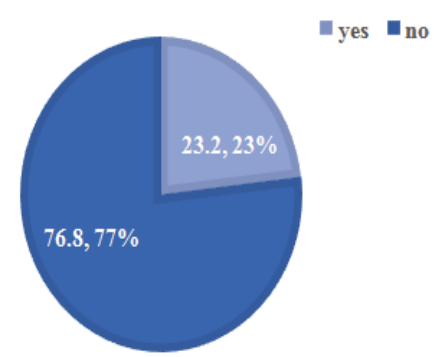

Figure 4: Respondents' knowledge of right technique of BSE (total number of BSE performers, $n=74$ ). 


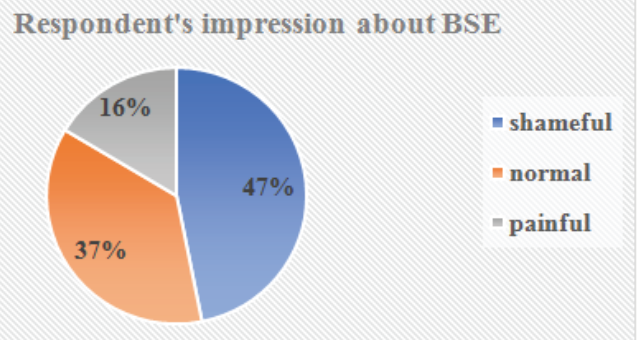

Figure 5: Respondents' impression about BSE (total number of BSE performers, $n=74)$.

\section{Discussion}

Breast cancer presents a very formidable health threat to all females. Informing young females about this serious disease is both a challenge and important investment in the health of future generations of women [11].

The role of BSE in the early detection of breast cancer has been studied by several authors. This study showed that the respondents had poor knowledge on BSE (40.1\%). The finding of this study is similar to those of studies conducted among female of final year medical student in Sudan which found that most respondent (86\%) were aware of BSE [12]. In Nigeria, study revealed that the women's level of knowledge of breast self-examination was low (20.39\%) [13]. The study in Austrian show that (92\%) of the women knew BSE [14], also study in Pakistan show that (19.3\%) of the study participants knew about the Breast self-examination [15]. On other hand, study was conducted during 2014-2015, among females in medical and non-medical colleges Saudi Arabia, regarding their knowledge levels about BSE (95.8\%) of medical students had heard of BSE in comparison to $(93.3 \%)$ of non-medical students [16]. We expected this finding as they living in a rural area and no previous orientation campaigns about BSE.

Meanwhile, for the practice of BSE, this study has shown that only (19\%) of respondents practiced BSE, this result is very least comparing to study in Saudi Arabia They found that (49.7\%) of medical students had carried out BSE previously in comparison to (35.71\%) of the non-medical students [16] and to study in Sao Paulo that BSE was performed by (90.3\%) of women [17]. But it is similar to Nigerian study, revealed that the women's level of practice of BSE was generally low (64\%) [13]. Also, in Sudan, Pakistan and Austrian; found that only two third, (mean score, $9.65 \% \pm 50.4 \%$ ) and only $(31 \%)$ of respondents respectively reported performing $[12,14,15]$.

According to Seif and A. Aziz [18] in Egypt, BSE is recommended monthly for women aged 20 and over as a screening modality for early detection of breast cancer (BC). With regard to the frequency of performing BSE, more than three quarters of our participants (84.6\%) claimed to practice BSE only rarely, that was similar to previous study done by Dr. Hazne Azira Romli, in Malaysia, revealed that the (77.3\%) claimed to practice BSE only rarely [19]. But Dr. Amir A. Hamza, in Sudan, found that $(64.5 \%)$ of respondents were practicing it regularly on a monthly basis [12]

With regard to knowing the right technique of BSE only fewest numbers (18\%) known the right technique. Similar to the studies done in Sudan and Pakistan, reported (46.5\%) and (9.6\%) of participants respectively can perform BSE correctly $[13,16]$.

Regarding attitude towards BSE, the result of our study revealed that $(66 \%)$ of the respondents had positive attitude towards BSE, this is in agreement with the result obtained by Dr. Emmanuel H. Daam conducted in Nigeria march 2018, revealed that positive mean attitude (3.07\%) towards BSE [13].
About (4.5\%) of respondents reported that the BSE was embarrassing to them. This is in agreement with the result obtained by Dr. Amir A. in Sudan where it was embarrassing in (14.5\%) [12].

In our study, the relation between age and excellent levels of knowledge found among the age range (18-25) were 40 females from 151 totals of excellent levels of knowledge. We expected that because this age range having more connection with social media and internet.

With regard to respondents' knowledge of definition of BSE according to educational level, our study revealed that excellent levels of knowledge detected among university students were (51) from 120 total of excellent levels of knowledge. We expected that because this educational level may have had orientation lectures and educational materials such as posters and leaflets freely available at universities.

\section{Limitation}

The study was confined to females at Altekaina village and cannot generalized to all Sudanese females, because Sudan involve many areas which different on population number, level of education, genetic and environmental factors.

Many answers in the questionnaire were subjected to female educational level and social limitations.

\section{Conclusion}

In conclusion, respondents in this study had positive attitudes towards BSE, but their compliance in knowledge and practicing BSE was poor. One of the females was a fried to be patient of breast cancer but when she performed the right maneuver after learnt it, she found it a benign lump so BSE decreased their delusion and fears about being patient of breast cancer. Therefore, it is important for continuing to continue education programs to play the important role of inculcating the knowledge and practice of BSE among reproductive age women of Altekaina village.

Based on the findings, we make the following recommendations for practice and further research.

In order to bridge the gap between knowledge and practice of BSE, the Ministry of Health should design and implement an intensive health education programme for schools, colleges, universities, hospitals and clinics. We suggest that campaigns be started to increase awareness about BSE and breast cancer screening for women. In addition, educational materials such as posters and leaflets should be freely available at hospitals and clinics to facilitate better learning.

Furthermore, researches are needed to identify the causes of inadequate knowledge of BSE and breast cancer screening among females in Sudan.

\section{Recommendations}

Based on the findings, we make the following recommendations for practice and further research.

In order to bridge the gap between knowledge and practice of BSE, the Ministry of Health should design and implement an intensive health education programme for schools, colleges, universities, hospitals and clinics. We suggest that campaigns be started to increase awareness about BSE and breast cancer screening for women. In addition, educational materials such as posters and leaflets should be freely available at hospitals and clinics to facilitate better learning.

Furthermore, researches are needed to identify the causes of inadequate knowledge of BSE and breast cancer screening among females in Sudan. 


\section{References}

1. Al-Naggar RA, Al-Naggar DH, Bobryshev YV, Chen R, Assabri A (2011) Practice and barriers toward breast self examination among malaysian women. Asian Pacific J Cancer Prev 12: 1173-1178.

2. Kayode FO, Akande TM, Osagbemi GK (2005) Knowledge, attitude and practice of breast self examination among female secondry school teachers in Ilorin, Nigeria. Euro J Scien Res 10: 42-47.

3. Sreedharan J, Muttappallymyalil J, Venkatramana M, Thomas M (2010) Breast Self-Examination: Knowledge and Practice among Nurses in United Arab Emirates. Asian Pac J Cancer Prev 11: 651-654.

4. Berry J (2017) Worldwide statistics on breast cancer.

5. El Saghir NS, Khalil MK, Eid T, El Kinge AR, Charafeddine M, et al. (2007) Trends in epidemiology and management of breast cancer in developing Arab countries: A literature and registry analysis. Int J Surg 5: 225-233.

6. Elgaili EM, Abuidris DO, Rahman M, Michalek AM, Mohammed SI (2010) Breast cancer burden in central Sudan. Int J Womens Health 2: 77-82.

7. Rosmawati NH (2010) Knowledge, Attitude and Practice of Breast Self-examination Among Women in a Suburban Area in Terengganu, Malaysia. Asian Pacific J Cancer Prev 11: 1503-1508.

8. Breast self-exam for breast awareness.

9. Taşçı A, Usta YY (2010) Comparison of knowledge and practices of breast self examination (BSE): a pilot study in Turkey. Asian Pacific J cancer prev 11: 1417-1420.

10. Selim Kılıç, Muharrem Uçar, Esra Seymen, Seçil İnce, Özlem Ergüvenli, et al. (2006) Determination of the knowledge and practice level of breast self-examination among the nurses of the gata hospital, the students of the gata nursing school and some female patients. Gülhane Med J 48: 200-204.
11. Akhtari-Zavar M, Hanafiah Jun M, Abdul Manaf R, Ismail IZ, Said SM (2011) Knowledge on Breast Cancer and Practice of Breast Self Examination among Selected Female University Students in Malaysia. MHSJ 7: 49-56.

12. Idris SA, Hamza AA, Hafiz MM, Ali MEA and El Shallaly GEHA (2003) Knowledge, attitude and practice of breast self examination among final years female medical students in Sudan. Int J Public Health Res 1: 6-10.

13. Daam EH, Kyamru JI, Wungakah SJ, Dabang TD, Dauda J (2018) Knowledge, attitude, practice of breast self-examination among women in Qua'an pan local government area of plateau state, Nigeria. Res journali's J Public Health 4: 1-15.

14. Janda M, Obermair A, Haidinger G, Waldhoer T, Vutuc C (2009) Austrian women's attitudes toward and knowledge of breast selfexamination. J Cancer Educ 15: 91-94.

15. Batool T, Sarwar H, Afzal M, Gilani SA (2018) Knowledge, Attitude and Practices of Women towards Breast Self-Examination in Rural Area of Lahore, Pakistan. APMC 12: 158-161.

16. Ibnawadh SK, Alawad MA, Alharbi SS, Alduawihi NA, Alkowiter FS, et al. (2017) Knowledge, attitude and practice of breast selfexamination among females in medical and non-medical colleges in Qassim University. J Heal Spec 5: 219-224.

17. Carelli I, Pompei LM, Mattos CS, Ferreira HG, Pescuma R, et al. (2008) Knowledge, attitude and practice of breast self-examination in a female population of metropolitan São Paulo. Breast 17: 270-274.

18. Seif NY, Aziz MA (2000) Effect of breast self-examination training program on knowledge, attitude and practice of a group working women. J Egypt Natl Canc Inst 12: 105-115.

19. Amir Firdaus Rosli M, Wan Fatimah Az-Zaharaa WK, Suresh R, Ahmad Zahin Z, Nur Ain M (2017) Knowledge and Attitude an Colorectal Cancer Screening among Sub-Urban Community in Sepang, Selangor. IJPHCS 4: 2289-7577. 